\title{
How Should We Treat the Vulnerable? Qualitative Study of Authoritative Ethics Documents
}

\author{
Ivana Zagorac, $\mathrm{PhD}$
}

\begin{abstract}
The aim of this study is to explore what actual guidance is provided by authoritative ethics documents regarding the recognition and protection of the vulnerable. The documents included in this analysis are the Belmont Report, the Declaration of Helsinki, The Council for International Organizations of Medical Sciences (CIOMS) Guidelines, and the UNESCO Universal Declaration on Bioethics and Human Rights, including its supplementary report on vulnerability. A qualitative analysis of these documents was conducted in light of three questions: what is vulnerability, who are the vulnerable, and how should the vulnerable be protected? The results show significant differences among the documents regarding the first two questions. None of the documents provides any guidance on the third question (how to protect the vulnerable). These results suggest a great discrepancy between the acknowledged importance of the concept of vulnerability and a general understanding of the scope, content, and practical implications of vulnerability.
\end{abstract}

Key words: Vulnerability, vulnerable populations, guideline, human research subject protection.

$\mathrm{T}$ he concept of vulnerability has achieved prominence in national and international medical research and health care ethical conduct guidelines. The conventional understanding considers vulnerability being "exposed to the possibility of being attacked or harmed, either physically or emotionally" (Latin, vulnerare, to wound). ${ }^{1}$ Normative projects (declarations, conventions, laws, professional codices) typically involve a call for minimizing vulnerability and protecting the vulnerable. Thus, it is to be expected that high-profile ethics documents take an interest both in framing the concept itself and in providing general instructions on how to deal with situations in which subjects are considered vulnerable. When dealing with the topic of vulnerability in the field of (bio)medicine, many authors refer to such authoritative documents, ${ }^{2-6}$ and yet systematic analysis is rare. ${ }^{7}$ Both scholars and policymakers have an interest in defining the criteria for recognizing vulnerable subjects and introducing measures for their protection. While many valuable efforts have been made to this end, the surprising outcome is that of a non-unified, and hence weak, account of the problem.

Some authors have suggested that the concept of vulnerability should be rejected entirely because it has become "too nebulous to be meaningful" ${ }^{8\left[{ }^{4} 4\right]}$ after being applied

IVANA ZAGORAC is an assistant professor at the Faculty of Humanities and Social Sciences, University of Zagreb, Croatia. Please send correspondence to Ivana Zagorac, Faculty of Humanities and Social Sciences, University of Zagreb, Ivana Lucica 3, HR-10000; email at izagorac@ffzg.hr. 
to different subjects under very different circumstances and in mutually incomparable contexts. ${ }^{9}$ While we avoid this conclusion, we agree with the identification of the problem. This paper uses a selection of authoritative ethics documents to highlight sources of disagreement and the different approaches used in understanding the nature of vulnerability, as well as to assess their sustainability. The aim of the paper is twofold: to explore how selected documents respond to the suggested ambiguity of vulnerability, and thus show their strength in providing guidance in questions related to the treatment of the vulnerable.

\section{Methods}

We have conducted an in-depth analysis of the Belmont Report, ${ }^{10}$ the Declaration of Helsinki (its 2000, 2008, and 2013 versions), ${ }^{11}$ CIOMS Guidelines (in all versions where vulnerability was mentioned), ${ }^{12-14}$ and the UNESCO Universal Declaration on Bioethics and Human Rights, ${ }^{15}$ including its report The Principle of Respect for Human Vulnerability and Personal Integrity. ${ }^{16}$ This analysis was conducted in light of three research questions: (1) What is vulnerability? (2) Who are the vulnerable? (3) How should the vulnerable be protected?

Selection criteria and rationale. The documents examined here were selected on several grounds. (1) They share the same goal: all of them wish to provide ethical guidance for (bio)medical research involving human subjects, while the UNESCO Declaration expands this goal to the provision of guidance in issues regarding human rights and bioethics. (2) They address issues of vulnerability: in most of them, vulnerability is one of the most important topics, while the IBC Report on Article 8 of the UNESCO Declaration deals exclusively with vulnerability. (3) They share the same methodology, from defining general principles to providing more or less detailed comments on the applications of these principles. (4) They also share a strong institutional background; the National Commission for the Protection of Human Subjects of Biomedical and Behavioral Research, the World Medical Association, the World Health Organization, and the United Nations Educational, Scientific and Cultural Organization. (5) They are highly influential: publications of these documents and each revision that some of them have undergone have been noticed by both the professional community and the public at large, and have been discussed intensively. All of the selected documents are highly respected and are often used as supporting material for national legislative and professional codices, as well as essential references for institutional review boards.

The Belmont Report. The Belmont Report is one of the leading documents concerning ethics and health care research. By 1979, when the Belmont Report was published, several other important ethics documents had already been adopted by many organizations. The Nuremberg Code (1947) had been known for more than three decades, and the Declaration of Helsinki had already undergone its first revision (originally published in 1964, revised for the first time in 1975). However, it was the Belmont Report that first introduced the notion of vulnerability.

The Declaration of Helsinki. The Declaration of Helsinki (DoH), developed by the World Medical Association (WMA), is "a statement of ethical principles for medical research involving human subjects, including research on identifiable human material 
and data" (Article 1). ${ }^{1[\mathrm{p} .}{ }^{50]}$ The document is addressed primarily to physicians, but also encourages others involved in medical research to adopt its principles (Article 2). ${ }^{11}$ The DoH was adopted in Helsinki in June of 1964, and its seventh revision was completed in October of 2013. During its half-century of existence, the text has become longer (the 2013 version is three times longer than the 1964 version) and revisions have become more frequent. ${ }^{17}$ The DoH has been revised three times in the past 15 years alone, and notes of clarifications have been added on two other occasions. Not only has the $\mathrm{DoH}$ come to have a great historical impact, but it has also become the most influential ethics document guiding the field. ${ }^{11}$ Vulnerability is first mentioned in the fifth revision of the DoH (2000). Our analysis includes this and the subsequent two revisions of the DoH.

The CIOMS Guidelines. The Council for International Organizations of Medical Sciences (CIOMS) was jointly established by WHO and UNESCO in 1949. In 2013, CIOMS membership included 49 international, national, and associate member organizations. The Council for International Organizations of Medical Sciences focuses on the field of the biomedical sciences. It issued its Proposed International Ethical Guidelines for Biomedical Research Involving Human Subjects in conjunction with WHO in 1982. In 1993, CIOMS issued the International Ethical Guidelines for Biomedical Research Involving Human Subjects, which superseded the Proposed Guidelines. The Guidelines were revised and updated in 2002, and this version is currently undergoing yet another revision. The changes announced are significant (major revisions of several guidelines, the merging of a few others, merging the entire document with the CIOMS Guidelines for Epidemiological Research). The revision of Guideline 13, which explicitly addresses research involving vulnerable populations, has not been announced. ${ }^{12}$ Our analysis includes CIOMS documents that mention vulnerability.

The Universal Declaration on Bioethics and Human Rights. The Universal Declaration on Bioethics and Human Rights was unanimously adopted in 2005 by all member states of UNESCO. It is implemented in international human rights law, although it is not legally binding. ${ }^{718-20}$ It aims at universality, and the resulting text was criticized at the time of its publication, ${ }^{21,22}$ however, the Declaration was adopted by many additional countries in the following decade despite this criticism. In 2013, UNESCO published The Principle of Respect for Human Vulnerability and Personal Integrity of the International Bioethics Committee of UNESCO (IBC), the sole purpose of which is to reflect on Article 8 of the UNESCO Declaration. With its core text and two appendices amounting to 54 pages, the IBC Report is the most thorough examination of the concept of vulnerability that has yet been conducted by any internationally recognized organization. Our analysis includes both the Declaration and the IBC Report.

\section{Results}

The Belmont Report. The Belmont Report ${ }^{10}$ outlines three basic ethical principlesrespect for persons, beneficence, and justice - and three applications of these principles to research conduct. Vulnerable subjects and populations are mentioned under all three applications. Concerning informed consent, it is argued that the voluntariness of informed consent may be compromised in cases where a research subject is under 
"undue influence." The Report further states that research subjects who are under commanding or controlling influence are "especially vulnerable." In the section on risk and benefit assessment, the Report argues that the justifiability of research with vulnerable populations itself should be demonstrated. The third application of general ethical principles deals with the question of selecting research subjects. The Report states that the burdens and benefits of research may be unjustly distributed even if research subjects are selected and treated fairly. Injustice arises "from social, racial, sexual and cultural biases institutionalized in society" (Part C, Section 3) ${ }^{10}$ which are out of the hands of researchers. Nevertheless, researchers should take them into account and consider distributive justice in selecting research subjects. Only this section makes explicit reference to vulnerable subjects. The Report lists four groups-racial minorities, the economically disadvantaged, the very sick, and the institutionalized - with a brief explanation of the substance of their vulnerabilities: members of these groups are either in dependent status and their capacity for free consent is frequently compromised, or they are easy to manipulate as a result of their illness or socioeconomic condition.

The Declaration of Helsinki (DoH). Vulnerability is first mentioned in the fifth revision of the DoH (adopted by the 52 ${ }^{\text {nd }}$ WMA General Assembly in Edinburgh, October 2000). In the Introduction, the DoH states that "some research populations are vulnerable and need special protection" (Article 8). ${ }^{11[\mathrm{p} 78]}$ What follows is a list of five groups: (1) the economically and medically disadvantaged, (2) those who cannot give or refuse consent for themselves, (3) those who may be subject to giving consent under duress, (4) those who will not benefit personally from the research, (5) those for whom the research is combined with medical care. ${ }^{11[p . ~}{ }^{78]}$ The basis upon which these groups were formed is unclear, and it is difficult to detect even a familial resemblance between them. Nevertheless, the explicit reference to vulnerable populations reflects the need for vulnerability to be integrated carefully into medical research planning.

Article 9 of the sixth revision of the DoH (adopted by the $59^{\text {th }}$ WMA General Assembly in Seoul, October 2008) addresses "particularly vulnerable research populations."11[p. 66] In this revision, the previous list of five groups is shortened to two: those who cannot give or refuse consent for themselves (group 2 from previous version) and those who may be vulnerable to coercion or undue influence (group 3). Later articles specify members of these groups as those who are incompetent/incapable (2) or those in a dependent relationship or under duress (3). In these cases, the DoH asks that informed consent be sought indirectly (Articles 27 and 29). Groups (4) and (5) from the 2000 version are mentioned in other articles of the revised 2008 version. Section $C$ of the $2008 \mathrm{DoH}$ lists additional principles for medical research combined with medical care, thus corresponding with a call for the special protection of group (5) from an earlier version of the $\mathrm{DoH}$. The special protection of group (4) is reflected in articles referring to the post-study ability of study subjects to access interventions identified as beneficial in the study (Articles 14 and 33) and in articles allowing medical research involving a "disadvantaged or vulnerable population or community" only if there is a "reasonable likelihood" that they will benefit from the research (Article 17). ${ }^{1[p .67]}$ The former refers to personal benefit, while the latter refers to the benefit of the entire population. The latter article is simultaneously the only place where the "disadvantaged" (1) are mentioned. Moreover, it is suggested that the "disadvantaged" are not "vulnerable" as was 
stated in an earlier version of the DoH. While this detail might be open to different interpretations, the absence of a reference to the lack of economic power or medical resources of potential research subjects is evident.

The seventh revision of the DoH (adopted by the $64^{\text {th }}$ WMA General Assembly in Fortaleza, October 2013) brought changes mostly regarding the organization of its articles (which lent the document a more coherent structure), a change in its overall tone ("should" is frequently replaced with "must"), and a change the terminology used: the connection between "incompetent/incapable" and informed consent which was previously expressed narratively was changed to the more straightforward classification of "capable/incapable of giving informed consent." Alongside these changes, this revision responded to heated discussion on some elements of earlier versions that had focused mostly on restrictions regarding the use of placebos. This latest revision of the $\mathrm{DoH}$ also introduced the obligation for appropriate compensation and treatment for subjects who were harmed as a result of participating in research (Article 15), which represents an important innovation of this newest version. However, the greatest change concerned vulnerable groups and individuals (Articles 19 and 20).

"Particularly vulnerable subjects" are now described as those who "may have an increased likelihood of being wronged or of incurring additional harm" (Article 19). ${ }^{11[p .51]}$ When it comes to medical research with vulnerable groups, the newest revision of the DoH adopts restrictions already mentioned in earlier versions: research involving vulnerable groups is justified only if it is responsive to the health needs or priorities of the group and if the group stands to benefit from the results of the research. However, this revision includes an additional restriction: such research is justified only if it cannot be carried out among a non-vulnerable group (Article 20). Exclusion criteria such as this are not entirely new to the $\mathrm{DoH}$, as this criterion was (and still is) an important part of its instructions on research involving subjects incapable of giving informed consent. Two out of three restrictions imposed upon medical research involving vulnerable groups and research involving individuals incapable of giving informed consent are the same (benefit for the group the research subjects represent, who are also the only possible choice of research subject). Subjects who are incompetent or incapable of giving informed consent are surely particularly vulnerable, and thus meet the definition of vulnerability set forward in Article 19 of the newest revision of the DoH. However, the $\mathrm{DoH}$ is concerned with all vulnerable groups and seeks "specifically considered protection."

The last revision of the $\mathrm{DoH}$ follows the negative trend in the number of groups explicitly labeled as vulnerable in previous revisions. In terms of a definition of vulnerability, it moves away from connecting vulnerability with informed consent. The rhetoric of the "disadvantaged" is omitted, while a new rhetoric referring to "wrongs" and "additional harms" is introduced.

The CIOMS Guidelines. Since its first version, the CIOMS Guidelines have paid special attention to vulnerable individuals and groups. The 1982 CIOMS Proposed Guidelines define vulnerability in terms of the compromised consent or subordinate position of research subjects. CIOMS 1991 Guidelines for Epidemiological Research awarded vulnerability the status of a principle, i.e. vulnerability was included, together with the principle of autonomy, into the general principle of respect for persons. The 
same document is concerned with the rules of distributive justice when vulnerable subjects are included in research. The last mention of vulnerable subjects in the 1991 CIOMS Guidelines for Epidemiological Research is in a section on the ethical review process. The title is "Vulnerable and dependent groups," and the list of these groups recapitulates the one from the 1982 CIOMS Proposed Guidelines, as well as adding new groups. The 1993 CIOMS International Guidelines superseded the 1982 Proposed Guidelines, and this version was then superseded by the 2002 CIOMS International Guidelines. Vulnerability lost the status of a principle in the process, but it was given its own guideline, the scope of the concept was enlarged, and even more groups were identified as vulnerable. ${ }^{7}$

The current version of the CIOMS Guidelines requires "special justification for inviting vulnerable individuals to serve as research subjects and, if they are selected, the means for protecting their rights and welfare must be strictly applied" (Guideline 13). Vulnerability is still mentioned under the principle of respect for persons, although as an "ethical consideration." The following definition of vulnerable persons is provided: "Vulnerable persons are those who are relatively (or absolutely) incapable of protecting their own interests. More formally, they may have insufficient power, intelligence, education, resources, strength, or other needed attributes to protect their own interests" (Guideline 13). The 2002 CIOMS Guidelines expand the scope of the notion of vulnerability compared to the 1982 version. This version also adopts the approach of listing vulnerable groups. Socio-economic and educational insufficiencies are added to the causes of vulnerability, which results in an even more exhaustive list of vulnerable groups.

The Universal Declaration on Bioethics and Human Rights. The Declaration mentions respect for human vulnerability and personal integrity in a section entitled "Principles": "In applying and advancing scientific knowledge, medical practice and associated technologies, human vulnerability should be taken into account. Individuals and groups of special vulnerability should be protected and the personal integrity of such individuals respected" (Article 8). In the section "Promotion of the Declaration," Article 24 additionally addresses vulnerability in the context of solidarity, arguing for "special regard for those rendered vulnerable by disease or disability or other personal, societal or environmental conditions and those with the most limited resources." The Declaration thus seems to be sending five messages: (1) vulnerability is a principle; (2) it is related to personal integrity; (3) there are two levels of vulnerability ("human" and "special"); (4) those "especially vulnerable" should be protected; (5) sources of vulnerability can be internal (e.g. disease) or external (e.g. societal or environmental conditions).

The Declaration itself has not been revised, instead relying on the publication of supplementary reports. The one that directly addresses the issue of vulnerability is The Principle of Respect for Human Vulnerability and Personal Integrity Report of UNESCO's International Bioethics Committee (IBC), published in 2013. ${ }^{16}$ The Report defines vulnerability as "a risk of a human being to be harmed in his or her physical and mental integrity" (Article 41). It further states that vulnerability is "an element of the human condition," an "essential feature of human nature," and "an inescapable dimension of the life of individuals" which "cannot be eradicated entirely." The Report argues that 
vulnerability beyond this kind of vulnerability constitutes "special vulnerability," which means that "there are individuals and groups that are especially prone to violation of personal integrity or disrespect for autonomy due to exploitation, deception, coercion and disregarded through the application and advancing of scientific knowledge, medical practice and associated technologies" (Article 41). According to the Report, the determinants of special vulnerability can be "natural," social, political, and environmental, and a detailed list of examples is provided (Articles 12, 13, and 14). Reiterating that the UNESCO Declaration is addressed to a broad audience, the Report concludes that we all share responsibility in preventing every human being from having to find themselves in a position of special vulnerability (Article 44 ).

\section{Discussion}

The results show that the common points among the documents examined regarding vulnerability are their references to "human vulnerability," their interest in describing the characteristics of those who are (particularly) vulnerable, and their call for the special protection of such subjects. However, these documents do not reach a consensus on any of these issues. The following shall address the key points and sources of disagreement regarding the conception of vulnerability: its dual nature (as an answer to the question of what vulnerability is), the problematic focus on classifying vulnerable subjects (offered as an answer to the question of who the vulnerable are), and the lack of guidance on how to protect the vulnerable.

What is vulnerability? Generally speaking, there is a certain confusion when it comes to the very definition of vulnerability. Both ethics documents and research ethics balance between two approaches we shall refer to here as "general" and "special." Briefly described, the first describes vulnerability as an inherent characteristic of human embodiment that we should properly acknowledge instead of trying to eradicate. The human condition is the core of this approach, and it argues that everyone is vulnerable by virtue of being human. The second approach focuses on a web of interpersonal relations and specific context-dependent variables that cause certain individuals or groups to be vulnerable. It attempts to define those features and point to subjects who, by virtue of having been affected by vulnerability-inducing factors, are worthy of special protection. We shall refer to this practice as the "classification methodology" This section will examine where the documents examined position themselves in regard to tensions between these two definitions of vulnerability.

The Belmont Report, the Declaration of Helsinki, and the UNESCO Declaration explicitly address the "particularly vulnerable," therefore implying the existence of those who are "generally vulnerable" - that is to say, these documents acknowledge general vulnerability but focus on special vulnerability. However, on the level of the texts themselves, it remains unclear whether the "particularly" and "generally" vulnerable groups differ or partially overlap.

General vulnerability is most thoroughly elaborated upon in the IBC Report, which is a supplement to the UNESCO Declaration. The IBC report itself echoes the definition of vulnerability found in the European Commission's Basic Ethical Principles in European Bioethics and Biolaw. ${ }^{23}$ The process of defining European principles resulted 
in the Barcelona Declaration Policy Proposals to the European Commission (adopted in November 1998 by Partners in the BIOMED II Project). The principles of autonomy, dignity, integrity, and vulnerability are offered therein as a conceptual framework within which Europeans should debate issues of bioethics and biolaw (where the term biolaw refers to the legal side of biomedical issues). The Barcelona Declaration deals with twofold vulnerability: on one hand, vulnerability "expresses the finitude and fragility of life", while on the other it is the "object of a moral principle requiring care for the vulnerable."23[p. 243] Such a broad definition is supported with references to contemporary European philosophy (the authors specifically mention Ricœur, Levinas, and Habermas), ${ }^{23[\text { p. } 241]}$ even though the definition of "vulnerability as conditio humana" has a much longer tradition in European thought. ${ }^{24,25}$ The Barcelona Declaration further states that the vulnerable are those under threat, and that all beings who have dignity are protected by the principle of vulnerability. Protection is understood here in both a negative and positive way: the principle requires not only non-interference with the autonomy, dignity, or integrity of beings, but also active assistance in the self-realization of their potential. ${ }^{23[\mathrm{p} .243]}$

The general vulnerability approach is not without its difficulties. It deals with the fact of human mortality without actually addressing different forms and degrees to which harm is inflicted, life is damaged, and dignity is offended. In other words, this is a definition of vulnerability that does not deal with wounds, but with (human) beings' general capacity to be wounded. Such a broad definition eliminates all degrees and forms of vulnerability as well as invulnerability. Some authors fear that the generalization and normalization of vulnerability turns it into a practically useless concept because it remains passive towards those who are worst off and need special protection. ${ }^{9,26,27}$ It has also been pointed out that there is a difference between those who are in danger of being harmed and those who have already been harmed, who have "fallen from the state of integrity to that of damaged individuality." ${ }^{24[\text {. 284] }}$ This view argues for a distinction between vulnerability (an essential attribute of mankind) and susceptibility (a signifier of suffering). In effect, protection from vulnerability brings forth an ethical claim that requires justice and respect for universal human rights, while susceptibility impels different social actions of care for those who are already suffering and are at risk of additional harm..$^{24,28}$

With regard to tension between the two definitions of vulnerability, the ethics documents examined here seem to acknowledge both, but define neither. The guidelines they offer only address the "particularly vulnerable," who are described through examples. It is assumed these are special cases wherein subjects have found themselves in a state of insufficiency beyond that shared by all human beings. The documents thus suggest that they have adopted a dual definition of vulnerability. This is most clearly the case in the IBC report, while the CIOMS Guidelines presents a single exception when it argues that vulnerability is the result of a subject acquiring "vulnerability-defining attributes." According to these guidelines, only when (and if) these attributes are present can a subject be considered vulnerable, i.e., worthy of special protection. Such exclusivity certainly offers user-friendly guidance when assessing cases potentially worthy of special protection. On the other hand, it recognizes only situations in which harm has already been done and in which measures protecting subjects from experiencing greater harm 
must be employed. Just as the general vulnerability approach remains ignorant to those

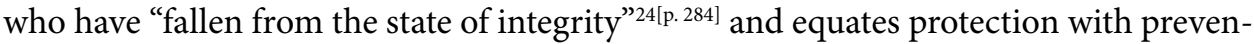
tion, the special vulnerability approach, when viewed as a clear theoretical concept, equates protection with special protection. There are no degrees, modalities, or different levels and scopes of protection as it is considered necessary only when suffering has already taken place, and is not considered a remedy but a safeguard against additional harm. It is too much to ask of ethics documents in the field of (bio)medicine to address issues of human suffering in general or to discuss the topic of vulnerability as conditio humana. However, they should not let it out of their sight completely, just as addressing (for example) the question of patient autonomy does not eliminate considerations of the concept of autonomy as such.

Who are the vulnerable? The question of "who the vulnerable are" is a question of who is worthy of special protection: the general vulnerability approach emphasizes universal (human) vulnerability, thus ignoring cases of those who are "extraordinarily vulnerable"29,30 and with them the concern for special protection measures. All of the documents examined here mention vulnerable individuals (subjects, persons) and groups (populations), while the CIOMS Guidelines mention vulnerable communities and countries. This document most frequently refers to "vulnerable classes," which is an expression that fits well with the classification methodology used in some of the documents. All of the documents seem to agree that an individual's vulnerability is constituted of a certain lack of power. However, they do not reach a consensus on exactly what kind of insufficiency makes someone particularly vulnerable. The Belmont Report, the CIOMS Guidelines, and the IBC report on Article 8 of the UNESCO Declaration all adopt a classification methodology consisting of a list of those who are worthy of special protection. When these lists are combined and repetitions excluded, the following groups are considered vulnerable in at least one of these documents: persons with serious, potentially disabling, or life-threatening diseases; persons with mental disorders; persons with disabilities; the institutionalized (patients, residents of nursing homes, etc.); prisoners; children; pregnant and nursing women, women in general in some parts of the world; the elderly; medical and nursing students, subordinate hospital and laboratory personnel, employees of pharmaceutical companies, members of the armed forces or police; racial and ethnic minorities; the poor; the unemployed; the homeless; nomads; refugees; asylum seekers; victims of natural disasters; politically powerless people; the illiterate; the insufficiently educated; persons unfamiliar with modern medical concepts; future generations.

It is apparent that, as the scope of the notion of vulnerability in documents broadens ("insufficient power to protect one's own interest," "other personal, societal, or environmental conditions," "limited resources"), the number of those who are considered particularly vulnerable increases. A consensus exists with regard to individuals incapable of free or informed consent, while lists of other vulnerable groups partially overlap between documents. A historical overview of transformations in criteria is hindered by the low number of documents, however it is apparent that the emphasis on incapability for informed consent has been lost over time, while the impact of "external" conditions has taken prominence. The oldest document (the Belmont Report, 1979) limits vulnerable individuals and groups to those whose capacity for free or 
informed consent is compromised or limited, and to those whose specific conditions expose them to manipulation. The definition of vulnerability presented in the newest document (the Declaration of Helsinki, 2013) is open enough to include individuals incapable of informed consent and those who might be under influence or duress and whose capacity for free informed consent is therefore compromised, as well as those considered disadvantaged by virtue of "external insufficiencies"7 and who are therefore at risk of being harmed or wronged.

It is interesting to note that the background papers created to assist in the formulation of the earliest document presented here, the Belmont Report, offer a detailed analysis of vulnerability that moves away from the consent-based definition. All of the contributions on the topic were made by Robert Levine, ${ }^{31-33,7}$ who argues that "particular attention" is necessary in recruiting research subjects who might be "incapable of protecting their own rights and welfare." ${ }^{33[p p . ~ 4-32]}$ Levine identifies three reasons for the lack of such power. An "uncomprehending" subject is classified incapable "largely by virtue of being unable to comprehend the information necessary to provide valid consent," 33[pp. 4-32] while a "dependent" subject is one in need of the assistance or direction of others, "connected in a subordinate relationship to another person or institution."33[pp. 4-90] As was shown earlier, the Belmont Report considers these subjects vulnerable. However, Levine explicitly introduces the "vulnerable" as the third group of those incapable of protecting their own rights and welfare. He describes vulnerable subjects as "those who are either capable of being wounded or defenseless against injury," 33 [pp. 4-85] (i.e., as "those who are the most susceptible to harm"31[pp. 2-52]). Levine's elaborations on the topic of vulnerability show a significant overlap of the definitions of the uncomprehending, dependent, and vulnerable subjects ${ }^{31,32}$ that remains present in a majority of later authoritative documents concerned with the protection of the vulnerable in medical research. However, "being wounded" and "susceptible to harm" were to be almost completely omitted as descriptors of vulnerability in the ensuing three decades, at least in widely recognized ethics documents. They would appear again in the latest revision of the Declaration of Helsinki, not as additional descriptors, but, interestingly enough, as the only descriptors of vulnerability.

To a certain degree, the classification methodology adopted in some of the documents can be justified on the grounds that they aim to provide guidelines in applying general ethical principles. On the other hand, critics have raised concerns that listing leads to labeling, ${ }^{26}$ which can result in the stereotyping, discrimination, stigmatization, and further exclusion of groups that are traditionally underrepresented in medical

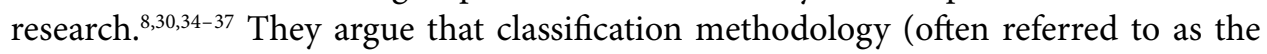
sub-population approach) exaggerates the protection of those who need it and forces protection upon those who might not need it. Simultaneously, such a methodology is blind to a variety of potential threats that an individual might face in a certain situation. Furthermore, the result of broadening the scope of the notion of vulnerability and using a methodology that assumes homogeneous classes of subjects is that anyone can be considered vulnerable, which is seen as problematic. ${ }^{4,8,38}$ This is a worrisome outcome for several reasons. If it were taken as an unexamined premise when designing a research study, hardly any research could take place. This is fostered by restrictive measures promoted by the documents themselves: research that includes vulnerable 
groups is allowed only if it cannot be conducted among a non-vulnerable group. Special protection of the particularly vulnerable does not necessarily mean they should be simply excluded from any research, but if the vast majority of subjects is considered vulnerable, special protection loses its meaning. Moreover, as the classification methodology has to assume that there are some who will not meet the criteria, it will in effect never meld with the perspective that sees vulnerability as conditio humana. With obsolete special protection classification methodology can lead to an ethical vacuum.

How should the vulnerable be protected? The general vulnerability approach claims that vulnerability is a feature of all (human) beings. Such a concept of vulnerability should not be considered of little practical value - on the contrary, it is claimed that it motivates our sympathetic openness to others, builds responsibility and global solidarity, provides grounds for global rights institutions, and, as some philosophers claim, is at the core of ethics. ${ }^{23,25,39-41}$ The UNESCO Declaration and its supplementary report on vulnerability are especially concerned with vulnerability interpreted in this way. Rather than talking exclusively about protection, they call for respect for human vulnerability. The rationale behind it is that, before arguing over whether vulnerability be eliminated or accepted, we must respect it. ${ }^{25}$ Respect for human vulnerability is explained by evoking the concept of personal integrity. The IBC report on Article 8 of the UNESCO Declaration states that there is an "integral relationship" between respect for human vulnerability and respect for the integrity of persons (Article 3). ${ }^{16}$. 9] This interpretation is reflected through interlinked references to vulnerability and personal integrity: for example, Article 41 of the IBC report defines vulnerability as "a risk of a human being to be harmed in his or her physical and mental integrity," ${ }^{16[\text {. } 37]}$ while Article 6 states that the "human condition implies vulnerability" and that "every human being is exposed to the permanent risk of suffering 'wounds' to their physical and mental integrity." $16[$ [. 13] The principle of respect for human vulnerability and personal integrity thus obliges us to consideration an interpretation of vulnerability as "an inescapable dimension of the life of individuals and the shaping of human relationships" (Article 6). ${ }^{16[\text { p. } 13]}$ The message is that we must be aware of the fact that we all are vulnerable to being "touched" by others, i.e. permanently open to being "wounded." Article 9 of the Report states that this interpretation of vulnerability calls on every human being "to fulfill the fundamental obligations we have one to another." ${ }^{[p . ~ 13] ~ T h u s, ~ a c c o r d i n g ~}$ to this approach, respect for vulnerability entails responsibility. Moreover, the Report expresses hope that "acknowledging the reality of vulnerability might provide a bridge between the moral 'strangers' of a pluralistic society, thereby enhancing the value of solidarity rather than mere individual interests" (Article 9). ${ }^{6[\text {. 13] }}$

As mentioned earlier, although they accept the concept of general vulnerability, both the UNESCO Declaration and its supplementary report do not ignore cases of individuals and groups who are "vulnerable in ways over and above that which the

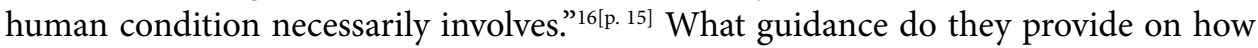
to treat these individuals and groups? Article 8 of the UNESCO Declaration provides only general instructions- "individuals and groups of special vulnerability should be protected"-adding that "the personal integrity of such individuals [should be] respected." It can be noticed that this formulation clearly links respect for personal integrity exclusively to "individuals and groups of special vulnerability", thus distort- 
ing the "integral relationship" between vulnerability and integrity promoted in the supplementary report. Responding to this apparent inconsistency, Patrão Neves argues that giving priority to those "classified as vulnerable" serves as a safeguard measure against reducing the vulnerable to their vulnerabilities (for example, against reducing the patient to his or her illness). Thus, the principle of respect for human vulnerability and personal integrity calls for the protection of the vulnerable against their being "wounded," as well as for respect for their integrity, which is interpreted as the "totality

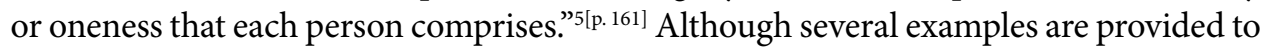
illustrate how this broadly constructed principle might guide practitioners in different types of medical practice, ${ }^{5[p p . ~}{ }^{162-163]}$ the actual normative force of the principle remains unclear, as do the ways and forms of protective measures aimed at those subjects the principle intends to serve.

One would expect that those documents primarily considering cases of "special vulnerability" offer clearer guidance on special protection. However, this is not the case. The protection of the vulnerable is concerned with those who should be protected, however, not only is there no word on measures of special protection, but the nature of the danger also remains unclear. The overall silence of the documents on measures of special protection might suggest that the question itself is misplaced. Perhaps a better question might be: What exactly should vulnerable subjects be protected against? According to examined documents, vulnerability is revealed through a certain relationship - "being dependent" (the Belmont Report), "easy to manipulate" (the Belmont Report), "incapable of protecting own interests" (CIOMS Guidelines), "increased likelihood of being wronged or of incurring additional harm" (the Declaration of Helsinki) - all of these constructions can function only with an offensive player on the other end. It suggests that the nature of vulnerability cannot be properly addressed without taking the nature of the danger into account - a fact explicitly mentioned only in the Belmont Report. It was only in the latest revision of the Declaration of Helsinki, the newest document examined here, that a similar perspective was suggested. ${ }^{11[p .51]}$ The newest revision of the Declaration of Helsinki seems to be following the path already laid down in the literature on focusing on harms and wrongs, thus shifting attention towards specific circumstances rather than towards the characteristics of subjects. ${ }^{3[\mathrm{p} .} 19$ 6],8[p. 44],26,42 This shift from the "protection of" (the vulnerable) to "protection against" (harms and wrongs) respects the fact that vulnerabilities reveal themselves in relation to something and in a specific context. Such an approach to the special protection issue emphasizes the need for tailored instead of generic protection, where the latter often results in the exclusion of those whom research labels vulnerable. ${ }^{43[\mathrm{p} .130]}$ In fact, the main purpose of special protection in this setting is to safeguard vulnerable subjects within the research process (in all its phases and aspects) against possible harm, not against their very participation in research. It is true that many subjects are vulnerable, but they are not identically vulnerable, ${ }^{3[\mathrm{p} .196]}$ and therefore should not be treated in a uniform way. Literature offers a variety of possible approaches on how to identify "special need" and provide "tailored" special protection: for example, one approach offers a list of markers for the occurrence of identifiable harm within the research context; ${ }^{42}$ an "analytical approach" aims to identify the morally relevant features of vulnerability and determine supplementary measures required to address these vulner- 
abilities ${ }^{44,45}$ while a "diagnostic approach" requires the identification of that morally protected interest that is at risk in a given research or health care setting, the reasons for its being so, and those involved in the duty of protection. ${ }^{43}$ None of these proposals denies that some features can make a subject vulnerable in almost every context (as is the case, for example, with children). They are also in agreement over the fact that one feature might render a subject vulnerable in one context, but not in the other, and that subjects must be protected in a particular setting which reveals (or even produces) $)^{30}$ their vulnerabilities. The main intention of these (and several other) approaches is to offer guidance on how to substitute generic protection with tailored protection, which is determined by influences on the subject (potential harms and wrongs) and not by the characteristics of the subjects themselves (e.g., poor, undereducated, members of minorities). Further, the conceptual shift from the "protection of" to "protection against" places the normative force of the claim to special protection in wrongs and harms, which seems far less problematic than connecting it with vulnerability itself. Naturally, there are still a number of unresolved issues, one of them being the relationship of special vulnerability to general vulnerability, as both types of vulnerability are, after all, located in the same subject. The interpretation of vulnerability offered in the Declaration of Helsinki seems to provide a good starting point for further discussions on the nature, scope, contents, and practical implications of vulnerability.

\section{Conclusion}

This paper has attempted to determine what authoritative ethics documents in the field of (bio)medicine have to say on three questions: what is vulnerability, who are the vulnerable, and how should they be protected. We must conclude that none of these documents provides a clear answer to any of these questions. A clear definition of vulnerability is nowhere to be found, but this would be too much to ask of this type of document in any case. However, what one might expect is a particular framework within which the important concept of vulnerability would be situated. The documents do offer such a framework, although it must be reconstructed by reading carefully and decoding their common features from examples of "those who are vulnerable." The general vulnerability claim that everyone is vulnerable by virtue of being human faces problems in research and health care applications. The classification methodology employed by other approaches to shed light on the characteristics that separate vulnerable individuals from invulnerable ones has also proven weak and significantly flawed. Moreover, the documents that use this methodology do not provide guidance on the next step: how to protect the vulnerable. Generally speaking, it remains unclear what is meant by "special protection."

Attempts to describe vulnerability by identifying examples of vulnerable classes who should then be treated in an unspecified "special way" place a heavy burden on the members of ethics committees, who must assess whether proposed research meets ethical standards of conduct. As much as some groups are wrongly predetermined to be vulnerable through the possession of a certain vulnerability-defining attribute, members of ethics committees are implicitly characterized as ultimately rational humans who can clearly recognize markers of vulnerabilities not offered on lists and who can judge 
whether the proposed safeguard measures correspond with ethical concern for special protection. The shift from the "protection of" to "protection against", as suggested in the latest version of the $\mathrm{DoH}$, is a conceptual change that might help us better understand vulnerability by moving away from it.

\section{Acknowledgments}

This research was conducted as part of "The Concept of Vulnerability in Medical Ethics" project, supported under Marie Curie NEWFELPRO funding scheme (FP7-PEOPLE2011-COFUND program; Government of the Republic of Croatia and the Ministry of Science, Education and Sport, Croatia). The project was hosted by the Institute of Medical Ethics and History of Medicine, Ruhr University Bochum, Germany. I would like to thank Prof. Dr. Dr. Jochen Vollmann, Dr. Jan Schildmann, and Dr. Tanja Henking for their invaluable assistance in conducting research and for their suggestions at different stages of the writing of this manuscript.

\section{References}

1. Oxford Dictionaries. "Vulnerability." Available at: http://www.oxforddictionaries. com/definition/english/vulnerable?q=vulnerability\#vulnerable_6.

2. Zion D, Gillam L, Loff B. The Declaration of Helsinki, CIOMS and the ethics of research on vulnerable populations. Nat Med. 2000 Jun;6(6):615-7. http://dx.doi.org/10.1038/76174 PMid:10835665

3. Hurst SA. Vulnerability in research and health care; describing the elephant in the room? Bioethics. 2008 May;22(4):191-202.

http://dx.doi.org/10.1111/j.1467-8519.2008.00631.x PMid:18405317

4. Coleman CH. Vulnerability as a regulatory category in human subject research. J Law Med Ethics. 2009 Spring;37(1):12-8. http://dx.doi.org/10.1111/j.1748-720X.2009.00346.x PMid:19245598

5. Patrão Neves M. Article 8: respect for human vulnerability and personal integrity. In: ten Have H, Jean MS, eds. The UNESCO Universal Declaration on Bioethics and Human Rights: background, principles and application. Paris, France: UNESCO, 2009. Available at: http://unesdoc.unesco.org/images/0017/001798/179844e.pdf.

6. Solbakk JH. Vulnerability: a futile or useful principle in health care ethics? In: Chadwick $\mathrm{R}$, ten Have H, Meslin EM, eds. The SAGE handbook of health care ethics. London: SAGE, 2011.

PMCid:PMC4090805

7. ten Have $\mathrm{H}$. The principle of vulnerability in the UNESCO Declaration on Bioethics and Human Rights. In: Tham J, Garcia A, Miranda G, eds. Religious perspectives on human vulnerability in bioethics. Dordrecht: Springer, 2014. http://dx.doi.org/10.1007/978-94-017-8736-9_3

8. Levine C, Faden R, Grady C, et al. The limitations of "vulnerability" as a protection for human research participants. Am J Bioeth. 2004 Summer;4(3):44-9. http://dx.doi.org/10.1080/15265160490508954 
http://dx.doi.org/10.1080/15265160490497083

PMid:16192138

9. Wrigley A. An eliminativist approach to vulnerability. Bioethics. 2015 Sep;29(7):47887. Epub 2014 Nov 25.

http://dx.doi.org/10.1111/bioe.12144

PMid:25425540

10. National Commission for the Protection of Human Subjects of Biomedical and Behavioral Research. The Belmont Report: Ethical principles and guidelines for the protection of human subjects of research. Washington, DC: Department of Health, Education, and Welfare, 1979. Available at: http://www.hhs.gov/ohrp/human subjects/guidance/belmont.html.

11. Wiesing U, Parsa-Parsi RW, Kloiber O, eds. The World Medical Association (WMA) Declaration of Helsinki. 1964-2014 - 50 years of evolution of medical research ethics. Ferney-Voltaire, France: WMA, 2014. Available at: http://www.wma.net/en /30publications/32doh/index.html.

12. CIOMS (Council for International Organizations of Medical Sciences). About Us. Geneva: CIOMS, 2016. Available at: http://www.cioms.ch/index.php/2012-06-07 -19-16-08/about-us.

13. CIOMS (Council for International Organizations of Medical Sciences). International guidelines for ethical review of epidemiological studies. Geneva: CIOMS, 1991. Available at: http://www.cioms.ch/images/stories/CIOMS/guidelines/1991_texts_of _guidelines.htm.

14. CIOMS (Council for International Organizations of Medical Sciences) in collaboration with WHO (World Health Organization). International ethical guidelines for biomedical research involving human subjects. Geneva: CIOMS, 2002. Available at: http://www.cioms.ch/publications/guidelines/guidelines_nov_2002_blurb .htm.

15. UNESCO (United Nations Educational, Scientific and Cultural Organization). Universal declaration on bioethics and human rights. Paris: UNESCO, 2005. Available at: http://unesdoc.unesco.org/images/0014/001461/146180E.pdf.

16. UNESCO (United Nations Educational, Scientific and Cultural Organization). The principle of respect for human vulnerability and personal integrity of the International Bioethics Committee of UNESCO (IBC). Paris: UNESCO, 2013. Available at: http://unesdoc.unesco.org/images/0021/002194/219494E.pdf.

17. Carlson RV, Boyd KM, Webb DJ. The revision of the Declaration of Helsinki: past, present and future. Br J Clin Pharmacol. 2004 Jun;57(6):695-713.

http://dx.doi.org/10.1111/j.1365-2125.2004.02103.x

PMid:15151515 PMCid:PMC1884510

18. ten Have H, Jean M.S., eds. The UNESCO Universal Declaration on Bioethics and Human Rights: background, principles and application. Paris: UNESCO, 2009. Available at: http://unesdoc.unesco.org/images/0017/001798/179844e.pdf.

19. Langlois A. The UNESCO Bioethics Programme: a review. New Bioeth. 2014;20(1):3-11. http://dx.doi.org/10.1179/2050287714Z.00000000040 PMid:24979873

20. Cameron NM. Humans, rights, and twenty-first century technologies: the making of the universal declaration on bioethics and human rights. J Leg Med. 2014;35(2):235-72. http://dx.doi.org/10.1080/01947648.2014.913458

PMid:24896314 
21. Dev World Bioeth. 2005 Sep;5(3):iii-vi; 197-273.

22. Macpherson CC. Global bioethics: did the universal declaration on bioethics and human rights miss the boat? J Med Ethics. 2007 Oct;33(10):588-90.

http://dx.doi.org/10.1136/jme.2005.013797

PMid:17906057 PMCid:PMC2652798

23. Rendtorff JD. Basic ethical principles in European bioethics and biolaw: autonomy, dignity, integrity and vulnerability - towards a foundation of bioethics and biolaw. Med Health Care Philos. 2002;5(3):235-44. http://dx.doi.org/10.1023/A:1021132602330 PMid:12517031

24. Kottow MH. Vulnerability: what kind of principle is it? Med Health Care Philos. 2004;7(3):281-7. http://dx.doi.org/10.1007/s11019-004-6857-6 PMid:15679020

25. ten Have H. Respect for human vulnerability: the emergence of a new principle in bioethics. J Bioeth Inq. 2015 Sep;12:395-408. Epub 2015 Jul 10.

http://dx.doi.org/10.1007/s11673-015-9641-9

PMid:26160601

26. Luna F. Elucidating the concept of vulnerability: layers not labels. Int J Fem Approaches Bioeth. 2009;2(1):121-39.

http://dx.doi.org/10.2979/FAB.2009.2.1.121

27. Formosa P. The role of vulnerability in Kantian ethics. In: Mackenzie C, Rogers W, Dodds S, eds. Vulnerability: new essays in ethics and feminist philosophy. Oxford: Oxford University Press, 2014.

28. Kottow MH. The vulnerable and the susceptible. Bioethics. 2003 Oct;17(5-6):460-71. http://dx.doi.org/10.1111/1467-8519.00361

PMid:14959710

29. Rogers W, Mackenzie C, Dodds S. Why bioethics needs a concept of vulnerability. Int J Fem Approaches Bioeth. 2012;5(2):11-38. http://dx.doi.org/10.2979/intjfemappbio.5.2.11

30. Lange MM, Rogers W, Dodds S. Vulnerability in research ethics: a way forward. Bioethics. 2013 Jul;27(6):333-40. Epub 2013 May 30.

http://dx.doi.org/10.1111/bioe.12032

PMid:23718774

31. Levine RJ. The role of assessment of risk benefit criteria in the determination of the appropriateness of research involving human subjects. In: The Belmont Report. Ethical principles and guidelines for the protection of human subjects of research, Appendix Volume 1. The National Commission for the Protection of Human Subjects of Biomedical and Behavioral Research, 1979. Available at: https://videocast.nih .gov/pdf/ohrp_appendix_belmont_report_vol_1.pdf.

32. Levine RJ. The nature and definition of informed consent in various research settings. In: The Belmont Report. Ethical principles and guidelines for the protection of human subjects of research, Appendix Volume 1. The National Commission for the Protection of Human Subjects of Biomedical and Behavioral Research, 1979. Available at: https://videocast.nih.gov/pdf/ohrp_appendix_belmont_report_vol_1 .pdf.

33. Levine RJ. Appropriate guidelines for the selection of human subjects for participation in biomedical and behavioral research. In: The Belmont Report. Ethical principles 
and guidelines for the protection of human subjects of research, Appendix Volume 1. The National Commission for the Protection of Human Subjects of Biomedical and Behavioral Research, 1979. Available at: https://videocast.nih.gov/pdf/ohrp_appendix _belmont_report_vol_1.pdf.

34. Lyerly AD, Little MO, Faden R. The second wave: toward responsible inclusion of pregnant women in research. Int J Fem Approaches Bioeth. 2008 Fall;1(2):5-22.

http://dx.doi.org/10.2979/FAB.2008.1.2.5

PMid:19774226 PMCid:PMC2747530

35. Eckenwiler LA, Ells C, Feinholz D, et al. Hopes for Helsinki: reconsidering "vulnerability". J Med Ethics. 2008 Oct;34(10):765-6.

http://dx.doi.org/10.1136/jme.2007.023481

PMid:18827112

36. Grady C. Vulnerability in research: individuals with limited financial and/or social resources. J Law Med Ethics. 2009 Spring;37(1):19-27.

http://dx.doi.org/10.1111/j.1748-720X.2009.00347.x

PMid:19245599

37. Wild V. How are pregnant women vulnerable research participants? Int J Fem Approaches Bioeth. 2012 Fall;5(2):82-104.

http://dx.doi.org/10.2979/intjfemappbio.5.2.82

38. Forster HP, Emanuel E, Grady C. The 2000 revision of the Declaration of Helsinki: a step forward or more confusion? Lancet. 2001 Oct 27;358(9291):1449-53.

http://dx.doi.org/10.1016/S0140-6736(01)06534-5

39. Hoffmaster CB. What does vulnerability mean? Hastings Cent Rep. 2006 Mar-Apr;36(2):38-45.

http://dx.doi.org/10.1353/hcr.2006.0024

PMid:16604897

40. Turner BS. Vulnerability and human rights. Philadelphia: Penn State University Press, 2006.

41. Turner BS, Dumas A. Vulnerability, diversity and scarcity: on universal rights. Med Health Care Philos. 2013 Nov;16(4):663-70.

http://dx.doi.org/10.1007/s11019-013-9500-6

PMid:23846549

42. Schroeder D, Gefenas E. Vulnerability: too vague and too broad? Camb Q Healthc Ethic. 2009 Apr;18(2):113-21.

http://dx.doi.org/10.1017/S0963180109090203

PMid:19250564

43. Hurst S. Clarifying vulnerability: the case of children. Asian Bioethics Rev. 2015 Jun;7(2):126-38. http://dx.doi.org/10.1353/asb.2015.0018

44. Kipnis K. Vulnerability in research subjects: A bioethical taxonomy. In: National Bioethics Advisory Commission. Ethical and policy issues in research involving human participants, Volume II. Bethesda, MD: National Bioethics Advisory Commission, 2001. Available at: https://bioethicsarchive.georgetown.edu/nbac/human/overvol2 .html.

45. Kipnis K. Seven vulnerabilities in the pediatric research subject. Theor Med Bioeth. 2003;24(2):107-20.

http://dx.doi.org/10.1023/A:1024646912928

PMid:12943266 